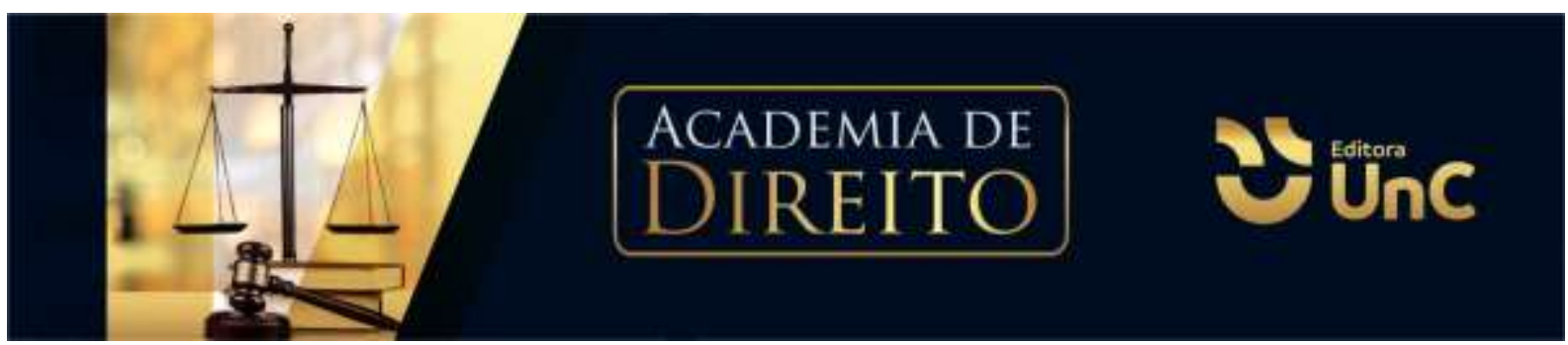

\title{
A TOMADA DE DECISÃO APOIADA COMO A MELHOR FORMA DE AUXÍLIO À PESSOA COM SÍNDROME DE DOWN
}

\section{DECISION MAKING SUPPORTED AS THE BEST FORM OF AID TO THE PERSON WITH DOWN SYNDROME}

\author{
Caroline Raldi ${ }^{1}$ \\ Adriane de Oliveira Ningeliski²
}

\begin{abstract}
RESUMO
Este artigo tem como objetivo identificar qual o melhor procedimento/instrumento civil que se aplica aos detentores da deficiência conhecida como Síndrome de Down, em qual a pessoa tem as capacidades apenas reduzidas e não totalmente anuladas para a construção de uma vida civil, com base no princípio básico da Dignidade da Pessoa Humana. Dessa maneira, foram buscadas ferramentas de auxílio para a tomada de decisões - Curatela e Tomada de Decisão Apoiada - a partir de uma pesquisa que seguiu a metodologia indutiva, citando diversos autores que discutem sobre os temas propostos. Por fim, o artigo analisa qual o instrumento civil mais adequado para ser utilizado pelos detentores dessa Síndrome em específico, baseado em todo o material coletado, do qual se extrai a tomada de decisão apoiada como boa forma de auxílio à pessoa com a deficiência chamada Síndrome de Down.
\end{abstract}

Palavras-Chave: Síndrome de Down. Dignidade da pessoa humana. Tomada de decisão apoiada.

\section{ABSTRACT}

This article aims to identify what is the best civil procedure / instrument that applies to people with disabilities known as Down Syndrome, in which the person has only reduced capacities and not totally canceled for the construction of a civil life, based on the basic principle of the Dignity of the Human Person. In this way, support tools were sought for decision making - Curatela and Supported Decision Making - based on a research that followed the inductive methodology, citing several authors who discuss the proposed themes. Finally, the article analyzes which is the most appropriate civil instrument to be used by the holders of this specific Syndrome, based on all the collected material, from which the supported decision-making is

\footnotetext{
${ }^{1}$ Acadêmica da $10^{a}$ Fase de Direito da Universidade do Contestado. Campus Mafra. Santa Catarina. Brasil. E-mail: carol.raldi@hotmail.com

2Doutoranda e Mestre em Direito, Centro Universitário Autônomo do Brasil, Docente e Pesquisadora da Universidade do Contestado. Santa Catarina. Brasil. E-mail: adriane@unc.br
} 
extracted as a good way of helping people with disabilities called the Syndrome Down.

Keywords: Down's syndrome. Dignity of human person. Supported decision making.

\section{INTRODUÇÃO}

A Síndrome de Down é uma alteração genética muito frequente na espécie humana. Tal alteração permite que a pessoa nasça e tenha uma vida relativamente normal, levando em conta alguns retardos no desenvolvimento, além de anomalias físicas.

A síndrome é uma condição crônica que impõem uma variedade de desafios tanto à criança quanto também à toda família. Diante de tais desafios e problemas decorrentes desta síndrome, é natural que surjam legislações e procedimentos para dar apoio à estas pessoas.

Dentre os procedimentos de apoio à vida civil, encontram-se a curatela e a tomada de decisão apoiada, ambos previstos na legislação civil brasileira. Sendo assim, a partir do conhecimento de tal síndrome, qual instrumento melhor atende as necessidades dos possuidores de Síndrome de Down, à luz do princípio da dignidade da pessoa humana e do estatuto da pessoa com deficiência? Este é o problema pelo qual a pesquisa foi elaborada.

O interesse pelo assunto surgiu através da preocupação com a assistência jurídica das pessoas com Síndrome de Down. Assim, e ante tal preocupação, cria-se a indagação em torno dos direitos que os detentores de deficiência possuem, bem como qual o melhor procedimento para prestar assistência aos possuidores desta deficiência na tomada de decisões da vida civil.

Sendo assim, a presente pesquisa utilizou o método indutivo para a abordagem, sendo realizada pesquisa de modo geral em doutrinas pertinentes acerca dos instrumentos de apoio à pessoa com deficiência. Após, passou-se para análise da melhor forma de apoio à pessoa com a Síndrome de Down.

Para tanto, o primeiro tópico aborda a dignidade da pessoa humana como princípio constitucional fundamental, trazendo qual a necessidade deste princípio a ser levado em consideração nesses casos. Após, no segundo tópico, serão analisados os instrumentos de apoio à vida civil que podem ser utilizados pelos 
deficientes, em específico a curatela e a tomada de decisão apoiada. E por fim, o terceiro tópico trata, de forma mais técnica, da Síndrome de Down, elencando seu conceito, bem como os sintomas, conhecimento técnico e as dificuldades que o deficiente e sua família encontram no decorrer da vida.

\section{O VIVER COM DIGNIDADE DA PESSOA COM DEFICIÊNCIA}

Todo ser humano nasce com direitos e garantias, não podendo estes serem considerados como uma concessão do Estado, já que alguns estes são criados pelos ordenamentos jurídicos, outros através de certa manifestação de vontade, e, ainda, alguns apenas são reconhecidos nas cartas legislativas.

Os direitos fundamentais constituem, em primeiro plano, direitos de defesa do indivíduo contra ingerências do Estado em sua liberdade pessoal e propriedade (SARLET, 2012, p. 142).

Sendo assim, os direitos fundamentais na condição de direitos de defesa, têm como objetivo, de certa maneira, a limitação do poder estatal, de forma que assegure ao indivíduo uma esfera de liberdade que lhe permita evitar interferências indevidas no âmbito de proteção do direito fundamental ou como forma de evitar agressões que possa vir a sofrer.

\footnotetext{
A título de síntese e de acordo com a plástica formulação de Gomes Canotilho, os direitos fundamentais cumprem a função de direitos de defesa dos cidadãos sob uma dupla perspectiva: (1) constituem, num plano jurídico-objetivo, normas de competência negativa para os poderes públicos, proibindo fundamentalmente as ingerências destes na esfera individual; (2) implicam, num plano jurídico-subjetivo, o poder de exercer positivamente direitos fundamentais (liberdade positiva) e de exigir omissões dos poderes públicos, de forma a evitar agressões lesivas por parte dos mesmos (SARLET, 2012, p. 142).
}

Sob esta ótica, é possível afirmar que os direitos fundamentais são, de fato, uma forma de proteção individual e coletiva perante o Estado, ainda que este não seja autoritário. Ainda, como posto acima, o direito fundamental nos reveste de legitimidade para exigir prestações ou omissões do Estado, de modo que os demais direitos sejam atendidos.

Sabe-se que os direitos fundamentais são classificados como de primeira, segunda, terceira e quarta gerações. A primeira compreende direitos civis e políticos 
essenciais ao ser humano, como por exemplo, direito à vida, segurança, propriedade privada, expressão, locomoção, entre outros; A segunda, trata de direitos que devem ser prestados pelo Estado, chamados de direitos sociais, culturais e econômicos, os quais são direito a saúde, saneamento, educação, habitação e outros (NOVELINO, 2009, p. 362-364).

Por sua vez, os direitos de terceira geração, e os mais relevantes para o presente estudo, estão ligados aos valores de fraternidade/solidariedade, pois voltados para a sociedade como um todo. Estes, são os relacionados ao desenvolvimento ou progresso, ao meio ambiente, à autodeterminação dos povos, São direitos transindividuais, em rol exemplificativo, destinados à proteção do gênero humano (NOVELINO, 2009, p. 362-364).

Acerca dos direitos de terceira geração:

[...] direitos que não se destinam especificamente à proteção dos interesses de um indivíduo, de um grupo ou de um determinado Estado. Têm por primeiro destinatário o gênero humano mesmo, em um momento expressivo de sua afirmação como valor supremo em termos de existencialidade concreta (BONAVIDES, 2003, p. 569).

Por outro lado, importante ressaltar que independente dos direitos de primeira à quarta geração o objetivo é a proteção da vida, liberdade, dignidade da pessoa humana e igualdade:

De outra parte, observa-se que, nada obstante a já relevada dimensão coletiva e difusa de parte dos novos direitos da terceira (e da quarta?) dimensão, resta, de regra, preservado seu cunho individual. Objeto último, em todos os casos referidos, é sempre a proteção da vida, da liberdade, da igualdade e da dignidade da pessoa humana, o que pode ser bem exemplificado pelo direito ao meio ambiente (SARLET, 2012, p. 37).

Assim, é possível vislumbrar que os direitos fundamentais foram criados, e são constantemente invocados, para garantir aquilo que é considerado fundamental para o homem, seja como direito individual ou coletivo.

Já os princípios jurídicos decorrem, de certo modo, dos direitos fundamentais, pois podem ser definidos como um conjunto de padrões de conduta presentes de forma explícita ou implícita no ordenamento jurídico. 
Princípios são enunciações normativas de valor genérico, que condicionam e orientam a compreensão do ordenamento jurídico, a aplicação e integração ou mesmo para a elaboração de novas normas. São verdades fundantes de um sistema de conhecimento, como tais admitidas, por serem evidentes ou por terem sido comprovadas, mas também por motivos de ordem prática de caráter operacional, isto é, como pressupostos exigidos pelas necessidades da pesquisa e da práxis (REALE, 2003, p. 37).

Assim, pode-se inferir que os princípios são orientadores, ou seja, têm a função de instruir o legislador ou o aplicador da norma.

Segundo alguns doutrinadores, a violação ou a não observância de um princípio pode anular uma decisão judicial.

Princípio traduz, de maneira geral, a noção de proposições fundamentais que se formam na consciência das pessoas e grupos sociais, a partir de certa realidade, e que, após formadas, direcionam-se à compreensão, reprodução ou recriação dessa realidade (DELGADO, 2011, p. 180).

Princípios, no âmbito constitucional pode ser divido em princípios fundamentais e princípios gerais. Os primeiros integram o Direito Constitucional positivo, ou seja, normas que contém a vontade do constituinte. Já os princípios gerais formam a teoria geral do Direito Constitucional, visto que envolvem conceitos gerais, relações e objetos (SILVA, 2005, p. 95).

Diante do acima exposto é possível afirmar que princípios informam, orientam e inspiram regras gerais. Ademais, devem ser observados quando a criação da norma, na sua interpretação e na sua aplicação.

[...] além da íntima vinculação entre as noções de Estado de Direito, Constituição e direitos fundamentais, estes, sob o aspecto de concretizações do princípio da dignidade da pessoa humana, bem como dos valores da igualdade, liberdade e justiça, constituem condição de existência e medida da legitimidade de um autêntico Estado Democrático e Social de Direito, tal qual como consagrado também em nosso direito constitucional positivo vigente (SARLET, 2012, p. 49).

O Princípio da dignidade da pessoa humana, por sua vez, é um dos preceitos fundamentais da CF/88, e está ligado, em seu íntimo, aos direitos básicos e sociais do homem. É versado no inciso III do artigo $1^{\circ}$ da CF/88 e implica respeito e proteção à integridade física, moral, à individualidade e espiritualidade do ser humano (MORAES, 2009, p. 21-22). 
Esse princípio afasta a ideia de predomínio de Estado e Nação, em detrimento da liberdade individual. A dignidade se tornou um valor espiritual e moral inerente à pessoa (MORAES, 2009, p. 21-22).

Atualmente, o Estado tem papel essencial e deve tomar providências, de modo que os indivíduos tenham condições mínimas para viver com dignidade. $\mathrm{O}$ referido princípio expressa um valor inerente a todo cidadão.

Esse valor deve ser respeitado por qualquer outra pessoa e, principalmente, por toda legislação jurídica, a fim de que o indivíduo não seja desrespeitado enquanto ser humano.

Dignidade da pessoa humana, constitui o núcleo essencial de todas as reivindicações e do qual constituem explicitações de maior ou menor grau (SARLET, 2012, p. 58).

\footnotetext{
Direito fundamental integrante da categoria de direitos negativos ou de defesa, também denominados diretos individuais ou de liberdade. Proclama o valor distinto da pessoa humana e tem, como consequência lógica, a afirmação de Direitos específicos de cada ser humano, sem distinções de gênero, raça, cor, credo, sexo e outras. Objetivo e fundamento dos direitos humanos da unidade ao sistema constitucional brasileiro (SILVA, 2007, p. 114).
}

Sendo assim, o princípio da dignidade da pessoa humana é um conjunto de princípios e valores que protege o indivíduo e sua dignidade, abrangendo a integridade física, moral e espiritual. Tal princípio assegura ao ser humano, sem distinção de gênero, cor ou sexo, os seus direitos perante a sociedade e o poder público.

\section{INSTRUMENTOS DE APOIO ÀS PESSOAS COM DEFICIÊNCIA: A LEGISLAÇÃO CIVIL PERTINENTE}

Os instrumentos de apoio civil nada mais são que ferramentas estabelecidas pelo governo para o auxílio e proteção do indivíduo possuidor de deficiências que carece de assistência, sendo ele total ou parcialmente incapaz, sempre baseado no princípio da Dignidade Humana, para que possa exercer sua vontade nos atos da vida civil. 


\title{
3.1 CURATELA
}

Antes mesmo da promulgação da Lei Brasileira de Inclusão da Pessoa com deficiência (Estatuto da Pessoa com Deficiência, Lei n. 13.146/2015), já havia uma discussão acerca da curatela, pois era o instituto que mais se aproximava da salvaguarda constante no artigo 12 da Convenção sobre os direitos das pessoas com deficiência, promulgada pelo Decreto n. 6.949/2009.

\begin{abstract}
Artigo 12
Reconhecimento igual perante a lei

1. Os Estados Partes reafirmam que as pessoas com deficiência têm o direito de ser reconhecidas em qualquer lugar como pessoas perante a lei.

2. Os Estados Partes reconhecerão que as pessoas com deficiência gozam de capacidade legal em igualdade de condições com as demais pessoas em todos os aspectos da vida.

3. Os Estados Partes tomarão medidas apropriadas para prover o acesso de pessoas com deficiência ao apoio que necessitarem no exercício de sua capacidade legal.

4. Os Estados Partes assegurarão que todas as medidas relativas ao exercício da capacidade legal incluam salvaguardas apropriadas e efetivas para prevenir [...].

5. Os Estados Partes, sujeitos ao disposto neste Artigo, tomarão todas as medidas apropriadas e efetivas para assegurar às pessoas com deficiência o igual direito de possuir ou herdar bens, de controlar as próprias finanças e de ter igual acesso a empréstimos bancários, hipotecas e outras formas de crédito financeiro, e assegurarão que as pessoas com deficiência não sejam arbitrariamente destituídas de seus bens (BRASIL, 2009).
\end{abstract}

A Lei n. 13.146/2015, por sua vez, alterou substancialmente o Código Civil quanto à capacidade civil das pessoas com deficiência, que, até então, eram ali previstas nos artigos $3^{\circ}$ e $4^{\circ}$, como absoluta ou relativamente incapazes (BRASIL, 2015).

A nova legislação assegura à pessoa portadora de deficiência, como regra, o direito ao exercício de sua capacidade civil de forma igualitária aos demais indivíduos, podendo ser aplicada a tomada de decisão apoiada, bem como a curatela, se necessárias (CNMP, 2016).

A curatela está prevista entre os artigos 1.767 a 1.783 do Código Civil (CC) (BRASIL, 2002).

Trata-se de um encargo público atribuído a alguém, por lei, "para reger e defender a pessoa e administrar os bens de maiores, que, por si sós, não estão em 
condições de fazê-lo, em razão de enfermidade ou deficiência [transtornos] mentais" (DINIZ, 2003, p. 1346).

A curatela é um instituto de proteção assim como a tutela, mas se difere por se destinar aos sujeitos maiores de idade que, por razões diversas, não podem cuidar sozinhos dos próprios interesses (CARVALHO FILHO, 2007, p. 1751).

\begin{abstract}
A curatela apresenta cinco características relevantes: a) os seus fins são assistenciais; b) tem caráter eminentemente publicista; c) tem, também, caráter supletivo da capacidade; d) é temporária, perdurando somente enquanto a causa da incapacidade se mantiver (cessada a causa, levantase a interdição); e) a sua decretação requer certeza absoluta da incapacidade (GONÇALVES, 2012, p. 592).
\end{abstract}

Sendo assim "com a curatela há pretensão de constituir um poder assistencial ao incapaz maior, completando ou substituindo sua vontade, protegendo, essencialmente seus bens, auxiliando em sua manutenção e impedindo sua dissipação" (DINIZ, 2016, p. 14).

Assim, a curatela, que se estabelece por decisão judicial, é uma medida de amparo à pessoa que não tenha condições de reger os atos de sua própria vida civil.

Para a decretação da curatela das pessoas detentoras de transtornos mentais é indispensável a prévia interdição, que se trata do instituto processual adequado à obtenção da declaração da incapacidade.

O processo que define os termos da interdição, conforme art. 747 do CPC/2015, deve ser promovido pelo cônjuge ou companheiro, pelos parentes ou tutores, pelo representante da entidade em que se encontra abrigado o interditando; ou, ainda, pelo Ministério Público (BRASIL, 2015).

Os artigos 749 e seguintes do Código de Processo Civil regulam o procedimento judicial parar decretação da interdição e nomeação de um curador ao interditado.

A petição inicial deverá ser endereçada ao juízo da Vara da Família, se houver, no domicílio do interditando. Além de atender aos requisitos do artigo 319 do CPC/2015, a exordial deve obedecer ao disposto no artigo 749, ou seja, "especificar os fatos que demonstram a incapacidade do interditando para administrar seus bens e, se for o caso, para praticar atos da vida civil, bem como o momento em que a incapacidade se revelou" (BRASIL, 2015). 
Após o recebimento da inicial, o interditando deverá ser citado para participar de entrevista com o magistrado, oportunidade em que o juiz tomará conhecimento da situação daquele que é pretendida a curatela (SÁ, 2020, p. 998).

$\mathrm{Na}$ sequência, conforme disposições do artigo 752, o requerido/interditando poderá se defender nos autos, opondo-se à sua interdição, impugnando o pedido. $O$ prazo é de 15 dias, contados da audiência de interrogatório (BRASIL, 2015).

Decorrido tal prazo, e existindo necessidade, o juiz determinará a realização de perícia médica "para avaliação da capacidade do interditando para praticar atos da vida civil" (BRASIL, 2015).

Realizada a perícia, tendo as partes se manifestado, bem como o Ministério Público, na condição de fiscal da lei, emanando parecer, o juiz decidirá sobre o pedido. Em caso de imposição da interdição, será nomeado curador, o prazo e os limites da curatela, conforme o estado e o desenvolvimento mental do incapaz (SÁ, 2020, p. 999).

A sentença de curatela deverá ser inscrita no registro de pessoas naturais e publicada na rede mundial de computadores, no site do tribunal no qual está vinculado o juízo que proferiu a sentença, e na plataforma de editais do Conselho Nacional de Justiça, onde permanecerá por seis meses, conforme estipulado pelo artigo 755, §3 do CPC/2015 (LÔBO, 2019, p. 440).

A curatela é uma medida extraordinária porque o incapaz poderá, se preferir, fazer uso de outro meio assistencial para que possa praticar atos da vida civil, que é a tomada de decisão apoiada (DINIZ, 2016, p. 21).

\subsection{TOMADA DE DECISÃO APOIADA}

Além dos tradicionais institutos da tutela e curatela surge a Tomada de Decisão Apoiada.

$\mathrm{O}$ art. 116 da Lei n. 13.146/2015 cria um tertium genus em matéria de modelos protetivos de pessoas em situação de vulnerabilidade. O Título IV do Livro IV da Parte Especial do Código Civil passou a vigorar acrescido do art. 1.783-A, consubstanciando 11 parágrafos (ROSENVALD, 2015). 
A tomada de decisão apoiada passou a existir no ordenamento jurídico brasileiro em 2016, com a vigência do Estatuto da Pessoa com Deficiência, artigo 1.783-A do Código civil.

Art. 1.783-A. A tomada de decisão apoiada é o processo pelo qual a pessoa com deficiência elege pelo menos 2 (duas) pessoas idôneas, com as quais mantenha vínculos e que gozem de sua confiança, para prestar-lhe apoio na tomada de decisão sobre atos da vida civil, fornecendo-lhes os elementos e informações necessários para que possa exercer sua capacidade (BRASIL, 2002).

Esse instituto é indicado nos casos em que a pessoa com deficiência possua capacidade de discernimento e manifestação de vontade, mas reconheça alguma dificuldade para conduzir sozinha determinados atos da vida civil.

\begin{abstract}
Diferentemente da tutela e da curatela, a tomada de decisão apoiada é faculdade concedida à pessoa com deficiência, para que escolha duas ou mais pessoas consideradas idôneas e que gozem de sua confiança, para que lhe aconselhem, orientem e apoiem na celebração ou não de negócios jurídicos, de natureza patrimonial. É apoio para exercício da capacidade legal, que Ihe atribuiu a Convenção e o Estatuto da Pessoa com Deficiência. Com esse procedimento não há perda ou limitação da capacidade legal, porque tem por escopo reforçar a segurança e a validade dos negócios jurídicos, em relação ao apoiado e a terceiros (LÔBO, 2019, p. 445).
\end{abstract}

Nesse contexto, o próprio interessado deve ingressar com pedido judicial, indicando no mínimo duas pessoas de sua confiança para serem suas apoiadoras na tomada de decisões da vida civil, conforme preceitua o artigo 1.783-A do Código Civil. (BRASIL, 2002).

O próprio deficiente poderá, para tanto, requerer a nomeação de duas pessoas aptas e idôneas, por ele indicadas, com as quais mantenha vínculos (de parentesco consanguíneo, socioafetivo; de afetividade) e que gozem de sua confiança para prestar-lhe apoio na tomada de decisão sobre atos da vida civil, fornecendo-lhe os elementos e informações necessários para o exercício de sua capacidade (DINIZ, 2016, p. 284).

Para tanto, mostra-se necessário que a pessoa com deficiência tenha certa lucidez e grau de discernimento, pois há a faculdade do próprio deficiente escolher as pessoas que exercerão o apoio na tomada de decisões.

No processo, o autor deve indicar as limitações e o prazo de vigência do acordo de apoio, no qual os apoiadores prestarão compromisso de respeito à 
vontade, direitos e interesses da pessoa que devem apoiar, conforme consta no artigo 1.783-A, $\S 1^{\circ}$ do Código Civil (BRASIL, 2002).

O juiz, assistido por equipe multidisciplinar, após oitiva do Ministério Público, ouvirá pessoalmente o requerente e as pessoas que lhe prestarão apoio, em concordância com o artigo 1.783-A, $\S 3^{\circ}$ do CC. A decisão tomada por pessoa apoiada terá validade e efeitos sobre terceiros, sem restrições, desde que esteja inserida nos limites do apoio acordado, segundo o $\S 4^{\circ}$ do mesmo artigo (BRASIL, 2002).

A tomada de decisão apoiada depende de aprovação judicial e de intervenção permanente do Ministério Público. Para tanto, os apoiadores devem antes celebrar termo, por instrumento público ou particular, que delimite o objeto, o alcance e as condições do apoio, bem como o prazo de vigência (LÔBO, 2019, p. 445-446).

Ainda em concordância com o art. 1.783-A, os $\S \S 9^{\circ}$ e $10^{\circ}$ dispõem que a pessoa apoiada pode, a qualquer tempo, solicitar o término de acordo firmado em processo de tomada de decisão apoiada; e o apoiador, por sua vez, pode solicitar ao juiz a exclusão de sua participação do processo, sendo seu desligamento condicionado à manifestação do juiz sobre a matéria (BRASIL, 2002).

\footnotetext{
$\mathrm{Na}$ tomada de decisão apoiada, o beneficiário conservará a capacidade de fato. Mesmo nos específicos atos em que seja coadjuvados pelos apoiadores, a pessoa com deficiência não sofrerá restrição em seu estado de plena capacidade, apenas será privada de legitimidade para praticar episódicos atos da vida civil.

$[\ldots]$

Enquanto a curatela e a incapacidade relativa parecem atender preferentemente à sociedade (isolando os incapazes) e à família (impedindo que dilapide o seu patrimônio), em detrimento do próprio curatelado, a tomada de decisão apoiada é uma medida promocional de autonomia que resguarda a liberdade e dignidade da pessoa com deficiência, sem amputar ou restringir indiscriminadamente os seus desejos e anseios vitais (ROSENVALD, 2015, p. 2-3).
}

Ainda para o autor, há uma gradação tripartite de intervenção na autonomia, qual seja: a) pessoas sem deficiência terão capacidade plena; b) pessoas com deficiência se servirão da tomada de decisão apoiada, a fim de que exerçam a sua capacidade de exercício em condição de igualdade com os demais; c) pessoas com deficiência qualificada pela curatela em razão da impossibilidade de autogoverno serão interditadas (ROSENVALD, 2015). 


\begin{abstract}
A tomada de decisão apoiada não exclui a curatela, nem a substitui, podendo com ela conviver, como ocorre na França com sauvegarde de justice, pois, p. ex., pelo art. 1.783-A e $\$ 11^{\circ}$, as mesmas disposições regerão ambos os institutos, no que atina à prestação contas, mas poderá provocar a ineficácia social da curatela por desuso. Apresenta-se, na verdade, como um concorrente da curatela (DINIZ, 2016, 283).
\end{abstract}

Além do mais, a tomada de decisão apoiada se encerra sob duas hipóteses: a) com a conclusão do negócio jurídico, ou, b) a qualquer tempo, se a pessoa com deficiência assim quiser, por ato de vontade, sem a necessidade de motivá-lo (LÔBO, 2019, p, 447).

Sendo assim, a tomada de decisão apoiada é um instrumento de apoio menos invasivo, se comparada ao instituto da curatela, como se este abrangesse aquela. Pois, o próprio deficiente consegue "administrar" quem lhe prestará o apoio, indicando as pessoas de sua confiança, bem como tem total liberdade para solicitar o término da vigência deste instrumento.

\title{
4 DA SÍNDROME DE DOWN, TRISSOMIA DO CROMOSSOMO 21 E A TOMADA DE DECISÃO APOIADA COMO FORMA DE APOIO NA VIDA CIVIL
}

A Síndrome de Down, como já mencionado anteriormente, é uma alteração genética frequente na espécie humana, a qual permite que a pessoa nasça com vida e se desenvolva de forma relativamente normal, levando em conta alguns retardos no desenvolvimento e anomalias físicas.

Como exemplos de alterações físicas e mentais podem ser citadas a dificuldade de aprendizagem, o atraso de fala, aumento de peso e estatura abaixo do normal, deficiência intelectual ou dificuldade em pensar e compreender, deslocamento da língua ou língua anormalmente grande, além de olho preguiçoso ou manchas. Também é comum a ocorrência de cardiopatia congênita, dedinho curvado, distúrbio de visão, doença da tireoide, imunodeficiência, linha única na palma da mão, músculos flácidos, obesidade, orelhas de implantação baixa, perda de audição ou respiração bucal (SERÉS et al., 2011).

Trata-se de "uma alteração genética que ocorre por ocasião da formação do bebê, no início da gravidez. A criança tem Síndrome de Down quando ocorre um erro na formação de uma das células reprodutoras" (CUNNINGHAM, 2008, p. 32). 
A Síndrome de Down é a alteração genética mais frequente na espécie humana, cuja frequência estimada no Brasil é de 1 em cada 700 nascimentos, segundo a Federação Brasileira das Associações de Síndrome de Down (SERÉS et al., 2011).

Embora essa Síndrome seja amplamente investigada, não se conhece a causa dessa alteração. Sabe-se, porém, que ela pode ocorrer de três modos diferentes: o primeiro é devido a uma não-disjunção cromossômica total. Dessa maneira, na medida em que o feto se desenvolve, todas as células acabariam por assumir um cromossomo 21 extra, sendo essa alteração equivalente a aproximadamente $96 \%$ dos casos (BISSOTO, 2005).

Uma segunda forma da alteração ocorre quando a trissomia não afeta todas as células e, por isso, recebeu a denominação de forma "mosaica" da Síndrome. A terceira forma que pode vir a acometer os indivíduos seria por translocação gênica, em que todo, ou parte, do cromossomo extra encontra-se ligado ao cromossomo 14 (BISSOTO, 2005).

Isso pode acontecer em todas as famílias independente de cor, raça, sem nenhuma relação com o nível cultural, social, ambiental, econômico etc. Ela pode ser diagnosticada na gestação quando a mãe está na fase do pré-natal, por meio de exames clínicos, como por exemplo a amniocentese (PAIVA, 2014, p. 3).

\begin{abstract}
A amniocentese é um método de diagnóstico pré-natal que consiste na punção transabdominal de uma pequena quantidade de líquido amniótico da bolsa amniótica para checar a saúde do bebê durante a gravidez. Esse procedimento pode ser realizado logo que exista quantidade suficiente do líquido amniótico em volta do feto. Para que possa ser recolhida uma amostra com segurança, o período ideal é entre 15 e 20 semanas de gestação (DÉA; et al, 2009, p. 27).
\end{abstract}

O diagnóstico também pode ser feito após o nascimento da criança, e inicialmente por parte das características que são muito comuns aos possuidores de Síndrome de Down, como por exemplo, cabeça mais arredondada, olhos puxados, boca pequena, entre outras (SERÉS, et al., 2011).

Neste sentido, enquanto o desenvolvimento de habilidades não-verbais parece melhorar ao longo da infância até a idade adulta, as dificuldades na linguagem podem se tornar mais acentuadas em relação aos pares ao longo do desenvolvimento. 
O sistema nervoso da criança com Síndrome de Down apresenta anormalidades estruturais e funcionais.

Existe uma lesão difusa, acompanhada de um funcionamento elétrico peculiar no desenvolvimento cognitivo dessa Síndrome, acarretando um rebaixamento nas habilidades de análise, síntese e a fala comprometida. Salienta, ainda, dificuldades em selecionar e direcionar um estímulo pela fadiga das conexões. Essas anomalias resultam em disfunções neurológicas, variando quanto à manifestação e intensidade (LURIA; TSKVETKOVA, apud SILVA; KLEINHANS, 2006).

Na Síndrome de Down existe uma limitação na transmissão e comunicação em muitos dos sistemas neuronais. São conhecidas cada vez mais as deficiências das ramificações dendríticas, da precoce redução dos neurônios responsáveis pela conduta associativa e pela comunicação nas áreas cerebrais umas com as outras (TRONCOSO; CERRO, apud SILVA; KLEINHANS, 2006).

Diferente de outrora, com o avanço da medicina e outros ramos da ciência, o sindrômico pode alcançar um bom desenvolvimento de suas capacidades pessoais e avançar crescentes níveis de realizações e autonomia. Sendo capaz de sentir, amar, aprender, se divertir e trabalhar. Em resumo, ele poderá ocupar um lugar próprio e digno na sociedade, sendo como qualquer outra criança normal, em certos momentos.

No entanto, apesar de tais avanços, é necessária atenção do Estado para com essas pessoas, tendo em vista algumas dificuldades, mas não incapacidade em exercer os atos da vida civil, bem como gerir bens, etc. Para tanto, existem os instrumentos de apoio ao deficiente, conforme já abordado.

\subsection{A DECISÃO APOIADA COMO FORMA DE AUXÍLIO À PESSOA COM SÍNDROME DE DOWN}

Notavelmente, os conceitos de Deficiência e Incapacidade foram desvinculados, ou seja, o deficiente é em regra, plenamente capaz, entretanto é possível que haja necessidade de adoção de procedimentos de auxílio para prática dos atos civis.

No caso dos detentores de Síndrome de Down, que possuem apenas um retardo intelectual e não incapacidade total, à luz do Princípio da Dignidade da 
Pessoa Humana, o procedimento que melhor se encaixa nas necessidades deles é a Tomada de Decisão Apoiada, uma vez que, quando adotada como instrumento civil para o sindrômico, não elimina sua capacidade de escolha e liberdade de expressão em relação as suas vontades.

Pois, conforme apresentada, a Tomada de Decisão Apoiada tem o condão de respeitar as vontades e preferências da pessoa apoiada, não podendo ser substituída pela vontade de seus apoiadores, tendo em vista que, conforme a lei prevê, serão apenas dois apoiadores que o próprio apoiado irá escolher, sendo aqueles que mantenham vínculo entre si e possuam confiança, devendo zelar os interesses da pessoa apoiada.

O referido instituto é diferente da Curatela, na qual o curador pode, em diversas ocasiões, substituir as vontades do curatelado nas decisões civis, fazendo com que o incapaz não goze de seus desejos. Logo, trata-se de uma espécie de instrumento mais invasivo, próprio para aqueles que são totalmente incapazes e impossibilitados de expressar suas vontades.

Sendo assim, a tomada de decisão apoiada trata-se de um instituto mais humanizado para pessoas que tenham certo grau de discernimento, o que ocorre na maioria dos casos de deficientes com a trissomia do cromossomo 21, pois preserva sua autonomia nas decisões a serem tomadas, vez que os apoiadores não terão total gerência sobre a pessoa com a deficiência.

\section{CONSIDERAÇÕES FINAIS}

Ante todo o exposto, é possível afirmar que os direitos fundamentais são uma espécie de ferramenta de proteção intrínseca ao homem, ou seja, todo homem nasce com seus direitos fundamentais, não sendo necessária a concessão ou o pleito por esses.

Ademais, o princípio fundamental da dignidade da pessoa humana implica no respeito e proteção à integridade física, moral, à individualidade e espiritualidade do ser humano. Em outras palavras, as ações estatais (do estado como um todo, envolvendo os três poderes) devem observar os princípios, como por exemplo, o direito fundamental da dignidade da pessoa humana, que rege em nosso ordenamento jurídico. 
Em observância aos direitos e princípios fundamentais, o Estado colocou à disposição da pessoa deficiente, ferramentas que auxiliam na tomada de decisões referente às questões da vida civil dela, através dos institutos da curatela e da decisão apoiada.

Tais institutos/instrumentos são de grande valia, em especial no caso da anomalia genética da Síndrome de Down, deficiência esta que permite o nascimento com vida, porém com algumas capacidades reduzidas, em razão da deficiência intelectual.

Por outro lado, a curatela é um encargo público atribuído por lei e destinada a pessoas que não tenham capacidade de exprimir suas próprias vontades, ou não possam reger adequadamente os atos da vida civil; A curatela é destinada, essencialmente, à administração dos bens do deficiente.

Logo, a curatela é mais invasiva, pois, por mais que possa ter caráter temporário, o incapaz tem sua dignidade violada, ao depender totalmente de alguém para administrar seus bens, bem como gerir sua vida.

Sendo assim, a tomada de decisão apoiada se mostra como uma ferramenta mais completa no caso de assistências às pessoas com Síndrome de Down, vez que a grande maioria dos sindrômicos pode exprimir suas vontades, e tem relativa facilidade em algumas coisas, como em alguns casos, a comunicação, a facilidade de entendimento, etc.

Como dito anteriormente, esse instituto é indicado nos casos em que a pessoa com deficiência possua capacidade de discernimento e manifestação de vontade, mas reconheça alguma dificuldade para conduzir sozinha determinados atos da vida civil.

Assim senso, a tomada de decisão apoiada, parece, realmente, um apoio para aquela pessoa que apenas tenha capacidades reduzidas, se comparadas à uma pessoa que não tenha a anomalia genética. A curatela, contudo, trata de uma substituição parcial da vontade do deficiente.

Portanto, a tomada de decisão apoiada é, logicamente, mais adequada às pessoas com Síndrome de Down, tendo em vista que esta deficiência permite que a pessoa tenha discernimento razoável para resguardar sua dignidade ao não depender inteiramente de ninguém ao administrar sua vida. 


\section{REFERÊNCIAS}

BISSOTO, Maria Luísa. O desenvolvimento cognitivo e o processo de aprendizagem do portador de Síndrome de Down: revendo concepções e perspectivas educacionais. Ciências \& Cognição, 2005. Disponível em:

http://www.cienciasecognicao.org/revista/index.php/cec/article/view/485. Acesso em: 10 maio 2020.

BONAVIDES, Paulo. Curso de Direito Constitucional. 13. ed. São Paulo: Malheiros, 2003.

BRASIL. Constituição da República Federativa do Brasil de 1998. Promulgada em 5 de outubro de 1988. Disponível em: http://www.planalto.gov.br/ccivil_03/ constituicao/constituicao.htm. Acesso em: 10 maio 2020.

BRASIL. Lei $\mathbf{n}^{0}$ 10.406, de 10 de janeiro de 2002. Instituiu o Código Civil. Disponível em: http://www.planalto.gov.br/ccivil_03/leis/2002/l10406.htm. Acesso em: 10 maio 2020.

BRASIL. Decreto $n^{\circ}$ 6.949, de 25 agosto de 2009. Promulga a Convenção Internacional sobre os Direitos das Pessoas com Deficiência e seu Protocolo Facultativo, assinados em Nova York, em 30 de março de 2007. Disponível em: http://www.planalto.gov.br/ccivil 03/_Ato2007-2010/2009/Decreto/D6949.htm. Acesso em 10 maio 2020

BRASIL. Diretrizes de atenção à pessoa com Síndrome de Down. Brasília: Ministério da Saúde, 2013. Disponível em: http://bvsms.saude.gov.br/bvs/ publicacoes/diretrizes_atencao_pessoa_sindrome_down.pdf. Acesso em: 10 maiO 2020.

CARVALHO FILHO, Milton Paulo. Código civil comentado. Barueri: Manole, 2007.

CUNNINGHAM, Cliff. Síndrome de Down: uma introdução para pais e cuidadores. 3. ed. Porto Alegre: Artmed, 2008.

DÉA, Vanessa Helena Santana Dalla; DUARTE, Edison. Síndrome de Down: Informações, caminhos e histórias de amor. São Paulo: Phorte. 2009

DELGADO, Maurício Godinho. Curso de direito do trabalho. 10 ed. São Paulo: LTr, 2011.

DINIZ, Maria Helena. A nova teoria das incapacidades. Revista Thesis Juris, São Paulo, 2016.

DINIZ, Maria Helena. O novo código civil: estudos em homenagem a Miguel Reale, São Paulo: LTr, 2003. 
GONÇALVES, Carlos Roberto. Direito civil brasileiro: direito de família. 9. ed. São Paulo: Saraiva, 2012.

LÔBO, Paulo. Direito civil: famílias. 9. ed. São Paulo: Saraiva Educação, 2019.

MORAES, Alexandre de. Direito constitucional. 24. ed. São Paulo: Atlas, 2009.

NOVELINO, Marcelo. Direito constitucional. 3 ed. São Paulo: Método, 2009.

PAIVA, Camila Foss; MELO, Camila Menezes; FRANK, Stéphanie Paese. Síndrome de Down: etiologia, características e impactos na família. Faculdade São Paulo. São Paulo, 2014. Disponível em: https://www.educaretransformar.net.br/wpcontent/uploads/2017/03/S\%C3\%8DNDROME-DE-DOWN-E-TIOLOGIA.pdf. Acesso em: 9 maio 2020.

REALE, Miguel. Lições preliminares de direito. 27.ed. São Paulo: Saraiva, 2003.

ROSENVALD, Nelson. A tomada de decisão apoiada: primeiras linhas sobre um novo modelo jurídico promocional da pessoa com deficiência. Revista IBDFAM, 2015. Disponível em: http://www.ibdfam.org.br/assets/upload/anais/253.pdf. Acesso em: 04 jun. 2020.

SÁ, Renato Montans de. Manual de direito processual civil. 5. ed. São Paulo: Saraiva Educação, 2020.

SARLET, Ingo Wolfgang. A eficácia dos direitos fundamentais: uma teoria geral dos direitos fundamentais na perspectiva constitucional. 11. ed. rev. atual. Porto Alegre: Livraria do Advogado, 2012.

SERÉS, August; QUIÑONES, Ernesto; CASALDÁLIGA, Jaume; CORRETGER, Josep; TRIAS, Katy. Síndrome de Down, de A a Z. Saberes, 2011.

SILVA, Guilherme Amorim Campos da. Dicionário brasileiro de direito constitucional: dignidade da pessoa humana. São Paulo: Saraiva, 2007.

SILVA, Maria de Fátima Minetto Caldeira; KLEINHANS, Andréia Cristina dos Santos. Processos cognitivos e plasticidade cerebral na Síndrome de Down. Revista Brasileira de Educação Especial, 2006. Disponível em: http://www.scielo.br/ scielo.php?script=sci_arttext\&pid=S1413-5382006000100009\&Ing=en\&nrm=iso. Acesso em 12 maio 2020.

SILVA, Maria de Fátima Minetto Caldeira. Tomada de decisão apoiada e curatela. medidas de apoio previstas na lei brasileira de inclusão da pessoa com deficiência. Brasília: Conselho Nacional do Ministério Público, 2016. Disponível em: https://www.cnmp.mp.br/portal/images/curatela.pdf. Acesso em: 04 nov. 2020.

Artigo recebido em: 14/10/2020

Artigo aceito em: 05/11/2020

Artigo publicado em: 29/07/2021 